Rogankov V. B., Shvets M. V., Rogankov O. V., Chikunkova T. A. Odessa National Academy of Food Technologies, Department of Physics and Material Science E-mail:vrogankov@yandex.ua

\title{
Supercritical heterogeneous nanostructure of fluids. Part 2. Its potential impact on creation of coupled stirlings with intermediate regeneration of heat
}

\begin{abstract}
New concept of a supercritical fluid (SCF) region is proposed to explain the set of experimental and numerical observations in which the conventional asymptotic scaling theory and its crossover extension achieve the limit of applicability. An existence of heterogeneous steady nanostructure in the wide ranges of supercritical parameters termed the non-gibbsian fluid (NGF)-phase was hypothesized by one of authors (V.B.R.) in the framework of FT (fluctuational thermodynamics)-model. The practical usage of a such structure may be quite promising. In particular, the proposed here concept of the Coupled Supercritical Heterogeneous (CSH)-stirling engine might be, in principle, realized. It is composed by two coupled stirling-rallis type cycles with the standard regeneration devices and, additionally, with the intermediate (internal) recuperation of heat. The closed construction of both sub-cycles and of the proposed CSH-stirling, in total, is its advantage in comparison with the external forms of recuperation in the open cycles. Thus, our aim is the usage of the established NGF-properties to formulate the concept of an effective stirling-type cycle with the most appropriate working fluid $\mathrm{SCF} / \mathrm{CO}_{2}$ (carbon dioxide) instead of the conventional here He (helium) and $\mathrm{H}_{2}$ (hydrogen) working fluids.

Keywords: fluctuation transition diagram, Stirling-Reilis type cycles, regeneration and internal heat recovery, environmental safety of closed thermal cycles.
\end{abstract}

1. Introduction The widespread belief is that in SCF-area (we use in this part of article the terminology and abbreviations of the previous part [14]) the sharp distinction between $g l$ - and $l l$-states similar to the observable difference between a subcritical $l$-phase and a subcritical $g$-phase disappears completely was called in question by the FT-diagram [14]. In accordance with the formulated FT2-region's concept, one cannot transform continuously $g l$-state of SCF into its $l l$-state and vice versa by only change of controllable $(P, T)$-parameters, i.e. without entering the FT2-region of NGF-phase. Its non-gibbsian, heterogeneous, locally-steady structure arises up to the higher limit of reduced pressure: $\pi_{\max } \approx 4$ achievable at reduced temperature: $\tau_{\text {max }} \approx 2$ along the critical isochore: $\omega=1$ of vdW-fluid (see Figs. 1, 2 in [14]). We claim now that namely this distinguishable feature of SCF makes it to be the finetunable $f$-system for a variety of aims. The term compressible SCF-regime used by Goodyear et al [15] for the similar simulated and apparently heterogeneous distributions of density seems to be adequate just for FT2-region. One may only complemented it by the property of the rapidly heat-transferable $S C F$. This addition is essential if the heat-engine should be created for the SCF-working fluid.

We have supposed earlier that the classical phenomenology of a spinodal decomposition as well as a homogeneous nucleation of metastable GPhs typical for $\mathrm{PhT1}$ have nothing in common with the hypothesized steady spatial structure of NGF. It is located in SCF-area within the exact $q \mathrm{sp} / \mathrm{ml}$-boundaries [14]. Its simulated snapshots look like the certain decorated lattice with three types of nano-cells filled by $\mathrm{gl}$, $l l$ - and ig-contents. To obtain such a supposedly inter-percolation structure we used the finite-range, well-determined by CP-parameters of a real substance LJ/FT- 
potential [16]. The advantage of FT-methodology is also explainable by the revealed local correlation between the density order parameter (simulated by FT-model) $\Delta \rho$ and the specific (or molar) entropy disorder parameter $\Delta s$ (introduced in our pervious works [17-20]). The described NGF-structure of a coupled order-disorder state appears suddenly at the instantaneous quench of $g l$ - or $l l$-gibbsian GPhs-states into FT2-region. Then, its evolution leads rather rapidly to the stationary (i.e. the independent explicitly on time) heterogeneous "landscape".

To the best of our knowledge, the highly effective closed Stirling cycle is recommended for the practical realization exclusively with the very light and lowtemperature working fluids such as $\mathrm{H}_{2}, \mathrm{He}$ or, even, air [1]. Its process at the typical ranges of $\Delta T$ and $\Delta P$ is localized in the wide area of Hard Fluid (i.e. outside of ZLcontour restricting the area of Soft Fluid and depicted in Figs. 1-3 of [14]). At first sight, this choice is appropriate if one takes into account the known advantages of the standard thermophysical coefficients for the light SCFs in comparison with those for steam $\left(\mathrm{H}_{2} \mathrm{O}\right)$ and/or for carbon dioxide $\left(\mathrm{CO}_{2}\right)$. However, the enormous mass and gabarits of formers working on $\mathrm{H}_{2}$ and $\mathrm{He}$ are the main obstacles for their wider usage.

On the other side, the intensive modern development and discussion of the supercritical Rankine and Brayton cycles [2-5] for the gas turbines is based, mainly, on such working fluids as $\mathrm{CO}_{2}$ and $\mathrm{H}_{2} \mathrm{O}$. Thus, authors [2] had not even included $\mathrm{H}_{2}$ and $\mathrm{He}$ in the long list of 35 perspective SCFs for this aim. They were recommended for the so-called transcritical Rankine cycle [6] entering the high-temperature two-phase $\mathrm{PhT1}$-region to provide an effective condensation process. This transcritical approach is, of course, explainable but the above constraints concerning the Stirling heatengine seem to be too restrictive. In particular, as a working SCF-fluid for stirlings, $\mathrm{CO}_{2}$ has the apparent advantages of the moderate CP-parameters, stability, low cost and, even, the relatively little environmental impact. The wider usage of $\mathrm{CO}_{2}$ by developing more advanced stirlings could increase the efficiency of heat-engines and reduce the climate-damaging effect widely discussable in the problem of $\mathrm{CO}_{2}$ emission.

In this work an attempt "to shift" the traditional position of the Stirling cycle for $\mathrm{He}$ and $\mathrm{H}_{2}$ namely to the FT2-region for $\mathrm{CO}_{2}$ will be discussed (Section 2). The goal is to use its advantages by means of the $\mathrm{SCF} / \mathrm{CO}_{2}$-working fluid and to avoid the known drawbacks of a Hard Fluid processing for $\mathrm{H}_{2}$ and He. The simplified and appropriate for the express-analysis of any cycle/substance FT-methodology of the caloric estimates will be proposed in Section 3. It is applicable to predict with the reasonable accuracy the parameters of characteristic knot-points as well as to construct the heat $(T, s)$-configuration of a cycle without the formidable caloric calculations based usually on the complex empirical thermal or fundamental EOS.

\section{Configuration of Coupled Supercritical Heterogeneous (CSH) stirling in FT-diagram \\ 2.1. Reduced PCS-correlation and location of the recommended CSH- stirling. The ideal cycle proposed by Stirling is composed of two isotherms and two isochores while the most popular in SCF-area ideal Brayton cycle of a gas turbine -}




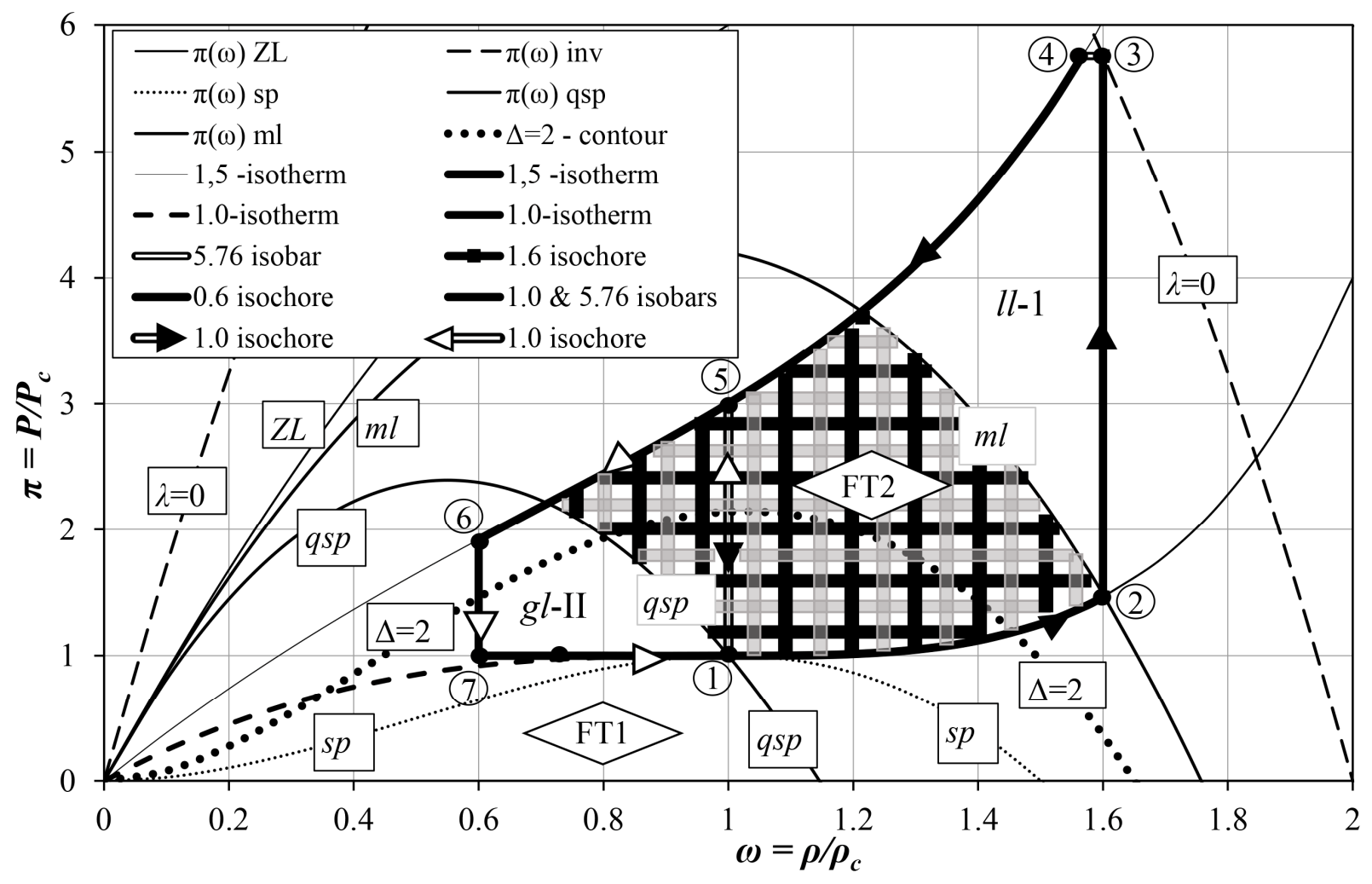

Fig. 1. Configuration of $\mathrm{CSH}$-stirling and its (1) $\rightarrow$ (2) $\rightarrow$ (3) $\rightarrow$ (4) $\rightarrow$ (5) $\rightarrow$ (1) I subcycle and (1) $\rightarrow$ (5) $\rightarrow$ (6) $\rightarrow$ (7) $\rightarrow$ (1) II sub-cycle in $g l(\mathrm{II})-, l l(\mathrm{I})$-regions of SCF in reduced $(\pi, \omega)$-plane (see also Fig. 1 in [14])

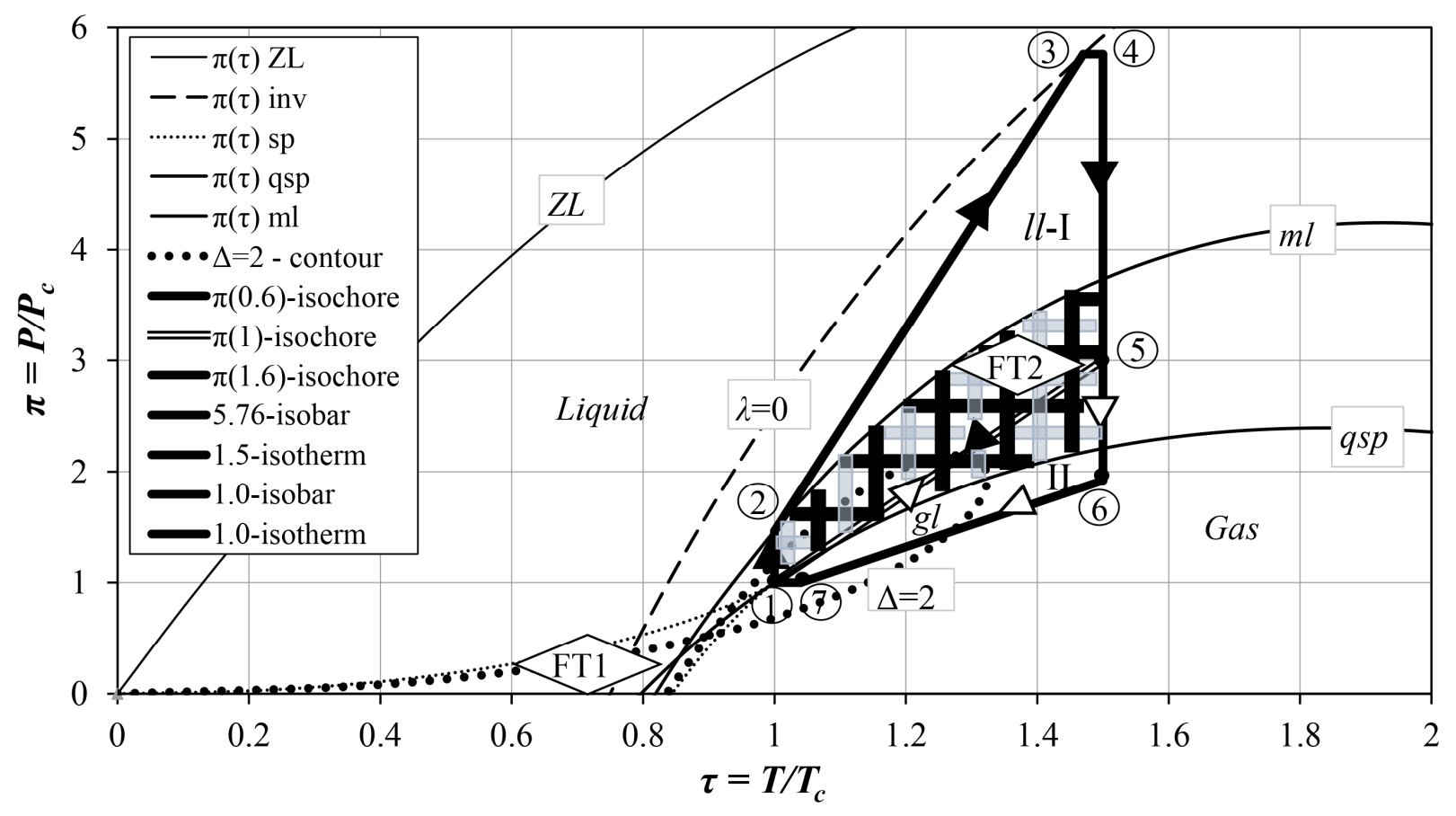

Fig. 2. Configuration of CSH-stirling and its (1) $\rightarrow$ (2) $\rightarrow$ (3) $\rightarrow$ (4) $\rightarrow$ (5) $\rightarrow$ (1) I subcycle and (1) $\rightarrow$ (5) $\rightarrow$ (6) $\rightarrow$ (7) $\rightarrow$ (1) II sub-cycle in $g l(\mathrm{II})-, l l(\mathrm{I})$-regions of SCF in reduced $(\pi, \tau)$-plane (see also Fig. 2 in [14]) 


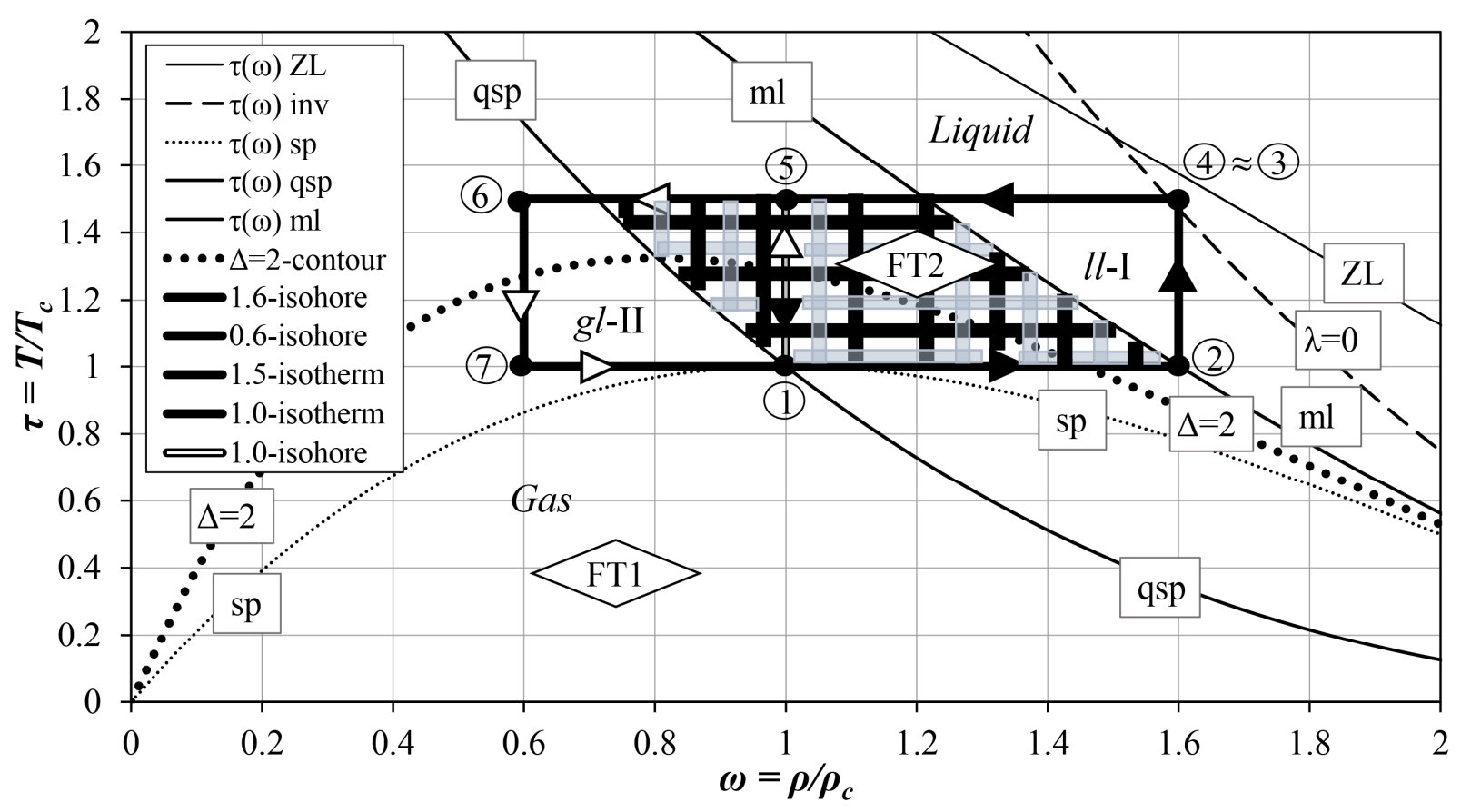

Fig. 3. Configuration of CSH-stirling and its (1) $\rightarrow$ (2) $\rightarrow$ (3) $\rightarrow$ (4) $\rightarrow$ (5) $\rightarrow$ (1) I subcycle and (1) $\rightarrow$ (5) $\rightarrow$ (6) $\rightarrow$ (7) $\rightarrow$ (1) II sub-cycle in $g l(\mathrm{II})-, l l(\mathrm{I})$-regions of SCF in reduced $(\tau, \omega)$-plane (see also Fig. 3 in [14])

two isobars and two isoentrops. This distinction is essential to emphasize that former is, in principle, more realizable as the actual economic engine than latter. Indeed, the presence of internal regenerator (Stirling himself called it economizer because the fuel economy) is the distinctive feature of stirlings and ericsons but not of the gasturbine or Brayton cycle with the external, at best, regeneration (recuperation) of heat. Such notice is useful to explain our attempt to augment the internal regeneration of the proposed CSH-stirling by the configuration of two coupled sub-cycles I and II shown in Figs. 1-3.

Two opposite directions of the internal regeneration in I-st (main) sub-cycle (black arrow-down) and II-nd (subsidiary) sub-cycle (white arrow-up) should coincide with the critical isochore $\omega=1$ to use its promising FT2-properties. Such properties are, first of all, the divergences of compressibilities and heat capacities at CP. Let us stress here that we do not intend to compare in any detail the different types of cycles and especially the devices of heat supply and/or heat rejection with the external recuperation. Instead of this, we admit that both coupled I and II sub-cycles are localized between two common heat reservoirs with the same higher and lower fixed temperatures: $\tau_{\max }$ and $\tau_{\min }$ preventing thermal equilibrium in both ones. Hence, the certain analogy of the proposed CSH-sub-cycles in SCF-region with the known functioning of a heat-pipe within the fixed temperature difference in the range of PhT1 should become obvious. Moreover, we suppose that one may tune the above higher and lower temperatures of reservoirs to induce inside of the given sub-cycles (and, as a result, in the total CSH-stirling) the steady nonequilibrium phase SCF-transition. 
Any phenomenological generalization of the well-known Ginzburg-Landau potential $[7,8]$ is not relevant here to adopt the above interpretation of the CSH-stirling.

Strictly speaking, the cycle depicted in Figs. 1-3 is only a little more complex than the simplest ideal stirling. It contains additionally two fragments of the higher isobar $\pi_{\max } 3 \rightarrow 4$ (I) and the lower isobar $\pi_{\min }=\pi=1$ (II) introduced to provide the optimum maintenance of the given temperature range: $\Delta \tau=\tau_{\max }-\tau_{\min }$. Thus, I-st (main) sub-cycle is formed by the lower (critical) isotherm $1 \rightarrow 2\left(\tau_{\min }=\tau=1\right)$ of a condensation-like process located completely within FT2-region. The next stage is the isochoric heating-compression $2 \rightarrow 3$ at the maximum chosen density $\omega_{\max }$ of a Soft Fluid ll-phase. It is combined with the short fragment of an isobaric expansion $3 \rightarrow 4$ to tune accurately the given higher temperature at the start of an isothermal vaporization-like process $4 \rightarrow 5$. Heat consumed by the working SCF from the upper external source-reservoir $\tau_{\max }$ expands sharply the gibbsian $l l$-phase and transforms it at the finish of $4 \rightarrow 5$ process into the heterogeneous vapor-like $(v l)$ structure of FT2-region. At last, the iso-choric cooling-expansion $5 \rightarrow 1$ occurred along the critical isochore concludes the I-st sub-cycle exactly at CP-location.

A combination of isochore with isobar similar to that depicted in points 3 and 7 is usually the sign of a so-called Rallis (or the generalized Carnot) cycle [1]. However, the implied meaning of such combination in the subsidiary II-nd sub-cycle is essentially other than that in the main I-st sub-cycle. To explain the distinction let us pay attention to the certain topologic similarity of the total CSH-shape with the wellknown steam Rankine cycle [9] operating inside of two-phase PhT1-region. Although belonging to the different regions of a phase diagram, both ones have the similar isothermal vaporization and isothermal condensation stages. Both ones should supposedly coincide below $T_{c}$ with the respective isobaric stages. This classical concept of $\mathrm{PhT} 1$ with a subcritical isotherm-isobar existing within two-phase region between the idealized gibbsian $g$-and $l$-phases GPhs implies the equality of chemical potentials and the gibbsian phase rule. It leads also to the set of rather meaningless theoretical infinities for measurable (i.e. finite in situ) $\beta_{T}, \alpha_{P}, C_{P}$-derivatives in any finite-volume two-phase system. Another its consequence is, most likely the "revelation of dividing line" by Woodcock [23] on the topmost segment of CXC in the $(P, \rho)$-plane located from the side of $l$-phase.

From a formal quantitative viewpoint it is actually the hard task to distinct the location of critical isotherm from the critical isobar in the FT2-region if one of the coordinates is the orthobaric density of $l$-phase $\rho_{l}(T)$ (Figs. 1,3). On the other side, such a distinction between the shapes of $P_{c}$ - and $T_{c}$-loci is easily observable by FTmodel from the side of $g$-phase. Indeed, it is shown in Fig 1 by the bold dashed line that the orthobaric $\rho_{g}(T)$-branch of real $f$-systems is identifiable with the vdWcritical isotherm $\tau=1$. In the $(P, \rho)$-plane its critical index is the classical value $\delta_{0}=3$ while the supposed flattening of the non-classical isotherm $T_{c}$ gives the higher scaling estimation $\delta \approx 9 / 2[21,22]$. FT-model admits that such flattening is re- 
lated with the uncertainty of the experimental critical isothermal data $P\left(\rho, T_{c}\right)$ obtained by their extrapolation in the hardly measurable region of the near-critical $g$ phase [9].

In any case, the subsidiary II-nd sub-cycle is composed by two isochores ( $\omega_{\min }$ and $\omega=1)$, one isotherm $\left(\tau_{\max }\right)$ and one (critical) isobar $\left(\pi_{\min }=\pi=1\right)$. The total CSH-stirling, as a result, demonstrates the formal similarity with the Rallis cycle but its condensation-like process is combined by two critical segments of $P_{c}$ - and $T_{c}$ loci.

2.2. Proposed scheme of CSH-stirling and its regeneration. For the convenience of reader all characteristic (recommended) knot-points as well as the changes of parameters along the isolines shown in Figs. 1-3 are represented in Table 1. We assume below that their values are applicable to real SCFs as well. To obtain the comprehensive initial estimates for the further development of CSH-stirling working on the real SCFs (Section 3), we have introduced the new criterion of the local thermophysical perfection $\gamma^{F T}$ for the direct $\gamma_{H}^{F T}$ and reverse $\gamma_{C}^{F T}$ Stirling cycles ( $H$ denotes here heating and $C$-cooling):

$$
\gamma_{H}^{F T}=\frac{P}{T}\left(\frac{d T}{d P}\right)_{H}=\left[\frac{P \delta v}{\delta q}\right]_{H}
$$

$$
\gamma_{C}^{F T}=\frac{T}{P}\left(\frac{d P}{d T}\right)_{C}=\left[\frac{\delta q}{P \delta v}\right]_{C}
$$

The ratio of the obtained useful work of engine to the supplied heat in Eq.(1a) and of the removed heat of cooling to the required work in Eq.(1b) corresponds to the efficiency of the infinitesimal heat engine $(\mathrm{H})$ and to the infinitesimal cooling device (C), respectively. Both above equalities for the universal criterion $\gamma^{F T}$ follow from the old but less known (in comparison with the conventional Clausius $(\mathrm{Cl})$ one) formulation of the Second Law proposed by Horstmann $(\mathrm{Hr})$ :

$$
\delta q=\left[T \frac{d P}{d T} \delta v\right]^{H r} \quad(a) \quad \delta s=\left[\int \frac{d q}{T}\right]^{C l} \quad(b) .
$$

This remarkably deep formulation emphasizes the compatible role of two controllable parameters $(P, T)$ for any types of the energy transformation. It is completely consistent with the Joule's notion of the mechanical equivalent of heat. The determinative role of pressure is certainly underestimated by the purely caloric formulation of Eq.(2b). It is based, however, on the fundamental Clausius' definition of a reversible specific entropy $s[\mathrm{~J} / \mathrm{kgK}]$. The possible choice of its unmeasurable by the direct thermophysical experiment initial value at $\mathrm{CP}$ will be discussed in Section 3. Obviously that the standard differential Clausius-Clapeyron equality derived [11] from the postulated assumption along the vapor-pressure curve $P_{v}(T)$ : $d \mu_{g}(T)=d \mu_{l}(T)$ is simply the particular finite-difference realization of Eqs.(1,2). It is applied to the supposedly reversible PhT1 occurred in vapor $v$-phase:

$$
\gamma_{v}^{F T}=R i_{v}^{F T} \equiv \frac{T}{P_{v}} \cdot \frac{d P_{v}}{d T}=\frac{\Delta h}{P_{v} \Delta v} .
$$


Table 1. Parameters of knot-points and their changes along isolines.

\begin{tabular}{|c|c|c|c|c|c|c|}
\hline$*)$ & knot & $\tau$ & $\pi$ & $\omega$ & \multicolumn{2}{|c|}{$\Delta T=T_{j}-T_{i}, \Delta P=P_{j}-P_{i}, \Delta \rho=\rho_{j}-\rho_{i}$} \\
\hline \multirow{2}{*}{$\mathrm{C} / \mathrm{RG}$} & \multirow{2}{*}{ (I)1(II) } & \multirow{2}{*}{1.0} & \multirow{2}{*}{1.0} & \multirow{2}{*}{1.0} & \multirow{2}{*}{$\pi_{\min }=1.0$} & $-\Delta T=0.04 T_{c}[\mathrm{~K}]$ \\
\hline & & & & & & $+\Delta \rho=0.4 \rho_{c}\left[\mathrm{~kg} / \mathrm{m}^{3}\right]$ \\
\hline \multirow{2}{*}{$\mathrm{C}$} & \multirow{2}{*}{ (I) 2} & \multirow{2}{*}{1.0} & \multirow{2}{*}{1.48} & \multirow{2}{*}{1.6} & \multirow{2}{*}{$\tau_{\min }=1.0$} & $+\Delta P=0.48 P_{c}[\mathrm{MPa}]$ \\
\hline & & & & & & $+\Delta \rho=0.6 \rho_{c}\left[\mathrm{~kg} / \mathrm{m}^{3}\right]$ \\
\hline \multirow{2}{*}{$\mathrm{RG}$} & \multirow{2}{*}{ (I) 3} & \multirow{2}{*}{1.47} & \multirow{2}{*}{5.76} & \multirow{2}{*}{1.6} & \multirow{2}{*}{$\omega_{\max }=1.6$} & $+\Delta T=0.47 T_{c}[\mathrm{~K}]$ \\
\hline & & & & & & $+\Delta P=4.28 P_{c}[\mathrm{MPa}]$ \\
\hline \multirow{2}{*}{$\mathrm{RG}$} & \multirow{2}{*}{ (I) 4} & \multirow{2}{*}{1,5} & \multirow{2}{*}{5.76} & \multirow{2}{*}{1.55} & \multirow{2}{*}{$\pi_{\max }=5.76$} & $+\Delta T=0.03 T_{c}[\mathrm{~K}]$ \\
\hline & & & & & & $-\Delta \rho=0.05 \rho_{c}\left[\mathrm{~kg} / \mathrm{m}^{3}\right]$ \\
\hline \multirow{2}{*}{$\mathrm{H} / \mathrm{RG}$} & \multirow{2}{*}{ (I) $5(\mathrm{II})$} & \multirow{2}{*}{1.5} & \multirow{2}{*}{3.0} & \multirow{2}{*}{1.0} & \multirow{2}{*}{$\tau_{\max }=1.5$} & $-\Delta P=2.76 P_{c}[\mathrm{MPa}]$ \\
\hline & & & & & & $-\Delta \rho=0.55 \rho_{c}\left[\mathrm{~kg} / \mathrm{m}^{3}\right]$ \\
\hline \multirow{2}{*}{$\mathrm{H}$} & \multirow{2}{*}{ 6(II) } & \multirow{2}{*}{1.5} & \multirow{2}{*}{1.92} & \multirow{2}{*}{0.6} & \multirow{2}{*}{$\tau_{\max }=1.5$} & $-\Delta P=1.08 P_{c}[\mathrm{MPa}]$ \\
\hline & & & & & & $-\Delta \rho=0.4 \rho_{c}\left[\mathrm{~kg} / \mathrm{m}^{3}\right]$ \\
\hline \multirow{2}{*}{$\mathrm{RG}$} & $7(\mathrm{II})$ & 104 & 10 & 06 & & $-\Delta T=0.46 T_{c}[\mathrm{~K}]$ \\
\hline & $/(11)$ & 1.04 & 1.0 & 0.0 & $\omega_{\min }-0.0$ & $-\Delta P=0.92 P_{c}[\mathrm{MPa}]$ \\
\hline
\end{tabular}

*) $\mathrm{H}$ - heating; $\mathrm{C}$ - cooling; $\mathrm{RG}$ - regeneration.

T-dependent generalized Riedel's parameter: $R i_{v}^{F T}$ has been introduced by FT-model [17-20]. Its thermodynamic coherence with the fundamental ratio of discontinuity in the enthalpy (latent heat) $\Delta h=T \Delta s$ to the discontinuity in the isobaric work expressed by the saturated specific volumes: $\Delta w=P_{v} \Delta v$ implies, additionally, the stringent equality between the chemical potentials: $\mu_{g}(T)=\mu_{l}(T)$.

The concept of mesoscopic distinctions between the real $f$-systems of a finite volume and those (imaginable) in the thermodynamic infinite-volume limit leads in FTmodel to the unavoidable split of a single $P_{v}(T)$-curve on two closely located bubble (b)-dew (d) curves below $T_{c}: P_{b}(T) \approx P_{v}(T) \geq P_{d}(T)$. They form the intermediate subcritical NGF-phase (called earlier interphase) as the alternative to the classical binodal/spinodal construction created in the framework of an unified $v d W$-type EOS. It is straightforwardly to demonstrate that above $T_{c}$ both criteria of thermophysical perfection calculated along SCF-isoentrope and SCF-isochore should have the different fluctuation meaning:

$$
\gamma_{H}^{F T}(s)=\frac{P_{s}}{T}\left(\frac{\partial T}{\partial P}\right)_{s}=\frac{P_{s} \alpha_{P}}{\rho C_{P}} \quad(a) \quad \gamma_{C}^{F T}(\rho)=\frac{T}{P_{\rho}}\left(\frac{\partial T}{\partial T}\right)_{\rho}=\frac{T}{P_{\rho}} \cdot \frac{\alpha_{P}}{\beta_{T}} \quad(b),
$$

but the same (positive or negative) sign determined by the sign of isobaric expansion $\alpha_{P}$. Both equalities are, in principle, necessary to provide the objective comparison by $\gamma^{F T}$-criterion of cycles in SCF-region. Here they can be easily (and similarly to Eq. (3) for PhT1) transformed into the finite-difference Ehrenfest's equalities for PhT2 [10,11]: 


$$
\gamma_{H}^{F T}\left(s_{c}\right)=\frac{P_{s} \Delta \alpha_{P}}{\rho \Delta C_{P}} \quad(a) \quad \gamma_{C}^{F T}\left(\rho_{c}\right)=\frac{T}{P_{\rho}} \cdot \frac{\Delta \alpha_{P}}{\Delta \beta_{T}} \quad(b) .
$$

We consider that the respective traditional analysis of PhT2 based on the questionable in PhT-vicinity of CP assumption of analyticity [10] does not provide the adequate information about the virtual spatial structure of SCF. To overcome this obstacle we concentrate our attention on the problem of reversibility adopted by the equilibrium thermodynamics for dynamical processes. For any real process the thermodynamic irreversibility is the concomitant feature of its finite-time realization. It follows from the itself adoption of NGF-existence either at $T \leq T_{c}$ or at $T>T_{c}$. The aforementioned strictly equilibrium equality: $\mu_{g}(T)=\mu_{l}(T)$ taken across the binodal should be rejected in such FT-construction, while the differential equality: $d \mu_{g}(T)=d \mu_{l}(T)$ taken alongside the bubble-dew boundaries of FT1, for example, remains meaningful. We refer now the interested reader to [17-20] for the other details of FT-model, since our attention will be concentrated below on the known irreversible Joule-Thompson (JT)-effect.

The JT-coefficient and its sign is the most directly connected, to our mind, with the problem of internal regeneration in stirlings and, in particular, with the problem of SCF-processes [12], in total:

$$
\left(\frac{\partial T}{\partial P}\right)_{h} \equiv-\left(\frac{\partial h}{\partial P}\right)_{T} /\left(\frac{\partial h}{\partial T}\right)_{P}=\frac{T\left(\alpha_{P}-\alpha_{P}^{i g}\right)}{\rho C_{P}} .
$$

It is defined as the isoenthalpic change in the controllable temperature with respect to that in the controllable pressure. Thus, the sign of its local $\lambda$-indicator shown in Figs. 1-3 in [14] depends completely on the sign of isobaric expansion $\alpha_{P}$ $\left(\alpha_{P}^{i g}=1 / T ; Z R / M=P / \rho T\right)$ :

$$
\gamma_{H}^{F T}(h) \equiv \frac{P_{h}}{T} \cdot\left(\frac{\partial T}{\partial P}\right)_{h}=\frac{Z R}{M} \cdot \frac{\beta_{T} \lambda}{C_{P}} \gtrless 0,
$$

were $\lambda=-\beta_{T}^{-1}+T \cdot \gamma_{v}$ [11]. This representation of the reduced isoenthalpic JTcoefficient by Eqs. $(6,7)$ can be compared with the isoentropic Eqs.(4a,5a) to explain the main idea of the proposed term FT2 in [14].

Equilibrium thermodynamics $[10,11]$ imitates any realizable in practice ultimately-irreversible adiabatic change of an equilibrium state just by its reversible isoenthalpic image. On the other side, the imaginable isoentropic reversible process corresponds to the supposedly instantaneous change of a state. It follows from comparison of Eq.(6) with Eq.(4a) that the only formal distinction between the irreversibility of former and the reversibility of latter is the local difference between the isobaric expansion coefficients $\left(\alpha_{P}-1 / T\right)$ and $\alpha_{P}$, respectively. Hence, the finitedifference Ehrenfest's Eq.(5a) for PhT2 in SCF-area should include additionally the fluctuation correction-drop in temperature: $\Delta \alpha_{P}^{i g}=\Delta(1 / T)$ to imitate the realistic isoenthalpic change. It is worth-while to note that the similar Ehrenfest's type transformation of the standard isoentropic index [10] $\gamma_{s}=-(v / P)(\partial P / \partial v)_{s}=1 /\left(P \beta_{s}\right)$ 


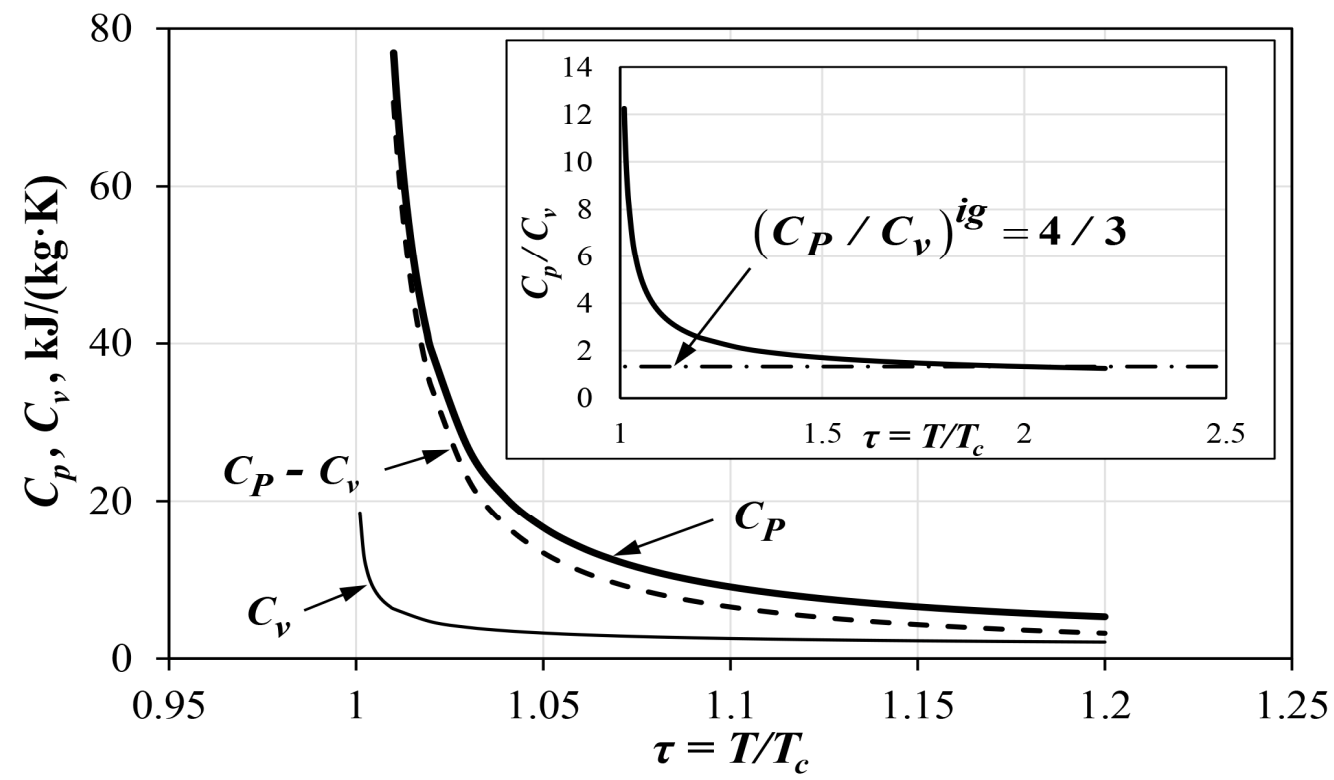

Fig. 4. The divergent trends of both heat capacities along the critical isochore $\rho_{c}$ at the gaussian near-critical approximation of Eqs. $(19 a, b)$ in [14]. The approach of CP in $(5 \rightarrow 1)$-process of I-sub-cycle and, vice versa, moving from it in $(1 \rightarrow 5)$ process of II-sub-cycle favours the effective heating of a regeneration porous nozzle for former but favours the effective heating of a working fluid for latter

leads also to the fluctuation correction-drop in pressure $\Delta \beta_{T}^{i g}=\Delta(1 / P)$ for the isoenthalpic change:

$$
\gamma_{s} \approx-\frac{v}{P} \cdot \frac{\Delta_{s} P}{\Delta_{s} v}=\frac{1}{P \beta_{T}} \cdot \frac{C_{P}}{C_{v}} .
$$

Its expected ig-ratio $\gamma_{s}^{i g}=\left(C_{P} / C_{v}\right)^{i g}$ (see, for comparison both Eqs.(19a,b) in [14]) can be obtained only by the deterministic ig-trend of $\Delta$-fluctuations $\left(P \beta_{T}\right)^{i g}=1$.

All above FT-correlations are of great importance to provide the correct description of regeneration process. For the vast majority of stirlings [1] they are realizable in the porous devices as the JT-ultimately-irreversible adiabatic (nonisoentropic) processes. To our mind, the term internal recuperator might be referred in the proposed CSH-stirling to a separated-flow contour-current heat exchanger formed by two coupled regenerators of I-st and II-nd sub-cycles. Both its regenerative components should act separately as usual regenerators within the respective cycles. Simultaneously, their localization along the critical isochore $\omega=1$ will provide the intensification of heating not only at the isochoric compression $2 \rightarrow 3$ (I) but also at the isochoric compression $1 \rightarrow 5$ (II). For latter the heat capacity is the sharply decreasing function of temperature along the critical isochore shown in Fig.4 for $\mathrm{CO}_{2}$ type of substance $\left(i=6, C_{P} / C_{v}=4 / 3\right)$.

\section{Caloric and convection flow estimates of CSH-segments.}

3.1. Non-equilibrium fluctuation form of FT-EOS. Hortsman's formulation Eq.(2a) provides a possibility to eliminate the entropy $s$-dependent Clausius' formula- 
tion Eq.(2b) of Second Law for the input heat $\Delta q$ from First Law written for a closed $f$-system to obtain the so-called thermodynamic EOS:

$$
P=T \frac{d P}{d T}-\frac{\Delta e}{\Delta v} \approx T \frac{d P}{d T}-P_{\text {int }},
$$

where the second approximate equality defines the internal pressure $P_{\text {int }}$ [13]. This form is equally applicable to the description of reversible and irreversible changes of parameters due to the general meaning of the Clausius' formulation adopted for Second Law (and excluded here). Another remarkable feature of Eq.(9) is the equal applicability to the ratio of differentials as well as to the ratio of finite differences $(\Delta e / \Delta v)$ :

$$
P=T\left(\frac{\partial P}{\partial T}\right)_{v}-\left(\frac{\partial e}{\partial v}\right)_{T} \equiv T\left(\frac{\partial P}{\partial T}\right)_{v}+\left(\frac{\partial e}{\partial \rho}\right)_{T} \cdot \rho^{2} .
$$

Thus, both First and Second Law non-equilibrium effects are involved in determin-ing the universal EOS of homogeneous by Eq.(10) and/or heterogeneous by Eq.(9) the parameter changes.

These observations were used to develop separately the 3-coefficient FT-EOS form for two fluid GPhs of $g$ - and $l$-states [17-20]:

$$
Z_{f}^{F T}-1=\frac{b_{f}(T) \rho-c_{f}(T)}{1-b_{f}(T) \rho}-\frac{a_{f}(T) \rho}{k_{B} T},
$$

where $c_{f}(T)$ is the fluctuation $T$-dependent coefficient (see, for comparison, [14]). The cohesion force contribution of internal pressure $P_{\text {int }}$ has the quite different value in the coexistent $f$-phases. It has been taken into account by the generalized vdWcoefficient $a_{f}(T)$ connected with the Riedel's parameter $R i_{v}^{F T}$ from Eq.(3):

$$
a_{f}(T)=-\left(\frac{\partial e}{\partial \rho}\right)_{T} \quad(a) \quad a_{v}(T)=-\frac{e_{l}-e_{g}}{\rho_{l}-\rho_{g}}=\frac{P_{v}\left(R i_{v}^{F T}-1\right)}{\rho_{l} \rho_{g}} \quad(b) .
$$

Of course, both $f$-dependent forms of Eq.(11) are strictly equivalent to Eq.(10) and Eq.(9), written as the thermodynamic identity:

$$
P_{v}=T \frac{d P_{v}}{d T}+\rho_{l} \rho_{g} \frac{e_{l}-e_{g}}{\rho_{l}-\rho_{g}} .
$$

Namely these correspondences were used by FT-model to derive the $T$ dependent $f$-coefficients without the adjustable parameters [18-20].

To illustrate the obvious advantages of FT-methodology at the analysis of any cycles, we have used below the simplified vdW-correlations with constant $(a, b)$ coefficients $[10,11]$ for all caloric functions:

$$
\begin{gathered}
s_{2}-s_{1}=\frac{i}{2} \frac{R}{M} \ln \left(\frac{T_{2}}{T_{1}}\right)+\frac{R}{M} \ln \frac{v_{2}-b}{v_{1}-b}, \\
e_{2}-e_{1}=\frac{i}{2} \frac{R}{M}\left(T_{2}-T_{1}\right)-\frac{a}{v_{2}}+\frac{a}{v_{1}},
\end{gathered}
$$




$$
h_{2}-h_{1}=\frac{i}{2} \frac{R}{M}\left(T_{2}-T_{1}\right)-\frac{2 a}{v_{2}}+\frac{2 a}{v_{1}}+\frac{R T_{2}}{M \varepsilon_{2}}-\frac{R T_{1}}{M \varepsilon_{1}},
$$

were $\varepsilon_{f}=[(v-b) / v]_{f} \equiv 1-(b \rho)_{f}$ - was termed the parameter of specific f-porosity (i.e. the reduced available specific volume) determinable in any $f$-state at the accepted in Eqs.(14-16) ig-assumption: $C_{v}=(i R) / 2 M=$ const . The "hierarchy" of Eqs.(1416) arisen due to the linearity of vdW-EOS in $T$ plays the essential role in the further FT-estimates. The first $T$-dependent contributions are the same for ig-model usable in the traditional energetic analysis [1]. However, the second $v$-dependent contributions are $b$ (excluded volume) - definable for entropy $s(T, \rho), a$ (cohesion force) - definable for internal energy $e(T, \rho)$ and, at last, $(a, b)$ - defi-nable for enthalpy $h(T, \rho)$. This observation is relevant to introduce the following factors of optimization for any real cycle.

The first FT-factor can be defined by the ratio of an internal energy difference $\Delta e \equiv e_{2}-e_{1}$ to that of an enthalpy $\Delta h \equiv h_{2}-h_{1}$ determined for the arbitrary segment $1 \rightarrow 2$ of a cycle:

$$
\delta_{i j}=\frac{\Delta e}{\Delta h} \approx \frac{\delta q-\delta w}{\delta q} .
$$

The second approximate equality is applicable to both finite-time equilibrium and non-equilibrium changes of thermodynamic parameters without the restrictive constraints at the determination of the input quasi-equilibrium heat: $\Delta h=T \Delta s$ and the output quasi-equilibrium work: $\Delta w=P_{v} \Delta v$. Hence, the smaller value $\delta_{i j}$ is not obligatory equivalent to the higher efficiency of a segment $i \rightarrow j$. The introduced by Eq.(17) FT-factor is useful, first of all, to estimate the total balance of an each caloric function (see Table 2) for the entire cycle or its closed sub-cycle. The less is absolute value of a total balance, the more effective should be realization of the respective cycle, in practice.

The second FT-factor of optimization is conjugated with $\delta$-factor, at least, to simplify the solution of the most complex theoretical problem of stirlings concerning the dynamical non-stationary stages of a cycle. In the well-established but ra-ther formidable knot-points methodology of a cycle analysis [1] the following gen-eral problem is posed. One has to integrate by the standard numerical methods the system of the nonlinear balance mass, momentum and internal energy (or entropy) equations complemented by the system of transport quasilinear gradient laws and by the chosen thermal EOS for the working fluid. All complexities of such conventional approach are well-known and widely discussable in the heat energetics.

The alternative way to the solution may be considered if the relevant convective one-dimensional velocity field $\vec{u}(\vec{x}, t)$ of a mechanic flow is the reliably determinable for the separate segments of a general contour. Let us remind that in accordance with the very simplified Bernoulli law for the stationary, laminar, non-viscous and incompressible flow its velocity becomes less if the pressure increases. As a result, both main dynamical stages of a cycle are 1) the slowing down (deceleration) of a flow at 
Table 2. The change of caloric vdW-functions calculated by Eqs.(14-17) for the entire CSH-cycle (a) and its sub-cycles I and II (b).

a) - entire $\mathrm{CSH}$-cycle

\begin{tabular}{|l|c|c|c|c|}
\hline Segment (a) & $\Delta s, \mathrm{~kJ} /(\mathrm{kg} \cdot \mathrm{K})$ & $\Delta e, \mathrm{~kJ} / \mathrm{kg}$ & $\Delta h, \mathrm{~kJ} / \mathrm{kg}$ & $\delta=\Delta e / \Delta h$ \\
\hline $1 \rightarrow 2 ; T_{\min }=T_{c}$ & -0.156 & -38.7 & -39.9 & 0.97 \\
\hline $2 \rightarrow 3 ; \rho_{\max }=1.6 \rho_{c}$ & +0.218 & +80.9 & +123.1 & 0.66 \\
\hline $3 \rightarrow 4 ; P_{\max }=5.76 P_{c}$ & +0.024 & +8.3 & +10.1 & 0.82 \\
\hline $4 \rightarrow 6 ; T_{\max }=1.5 T_{c}$ & +0.274 & +61.4 & +53.3 & 1.15 \\
\hline $6 \rightarrow 7 ; \rho_{\min }=0.6 \rho_{c}$ & -0.207 & -79.1 & -103.4 & 0.76 \\
\hline $7 \rightarrow 1 ; P_{\min }=P_{c}$ & -0.153 & -32.6 & -43.2 & 0.76 \\
\hline$\Sigma= \pm \Sigma$ & 0.516 & 150.4 & 186.5 & 0.81 \\
\hline
\end{tabular}

b) - sub-cycle I of CSH (main)

\begin{tabular}{|l|c|c|c|c|}
\hline Segment $(\mathrm{Ib})$ & $\Delta s, \mathrm{~kJ} /(\mathrm{kg} \cdot \mathrm{K})$ & $\Delta e, \mathrm{~kJ} / \mathrm{kg}$ & $\Delta h, \mathrm{~kJ} / \mathrm{kg}$ & $\delta=\Delta e / \Delta h$ \\
\hline $1 \rightarrow 2 ; T_{\min }=T_{c}$ & -0.156 & -38.7 & -39.9 & 0.97 \\
\hline $2 \rightarrow 3 ; \rho_{\max }=1.6 \rho_{c}$ & +0.218 & +80.9 & +123.1 & 0.66 \\
\hline $3 \rightarrow 4 ; P_{\max }=5.76 P_{c}$ & +0.024 & +8.3 & +10.1 & 0.82 \\
\hline $4 \rightarrow 5 ; T_{\max }=1.5 T_{c}$ & +0.143 & +35.5 & +24.3 & 1.46 \\
\hline $5 \rightarrow 1 ; \rho_{\min }=\rho_{c}$ & -0.229 & -86.0 & -117.6 & 0.73 \\
\hline$\Sigma_{(I)}=| \pm \Sigma|$ & 0.385 & 124.7 & 157.5 & 0.79 \\
\hline
\end{tabular}

b) - sub-cycle II of CSH (subsidiary)

\begin{tabular}{|l|c|c|c|c|}
\hline Segment $(\mathrm{IIb})$ & $\Delta s, \mathrm{~kJ} /(\mathrm{kg} \cdot \mathrm{K})$ & $\Delta e, \mathrm{~kJ} / \mathrm{kg}$ & $\Delta h, \mathrm{~kJ} / \mathrm{kg}$ & $\delta=\Delta e / \Delta h$ \\
\hline $1 \rightarrow 5 ; \rho_{\max }=\rho_{c}$ & +0.229 & +86.0 & +117.6 & 0.73 \\
\hline $5 \rightarrow 6 ; T_{\max }=1.5 T_{c}$ & +0.131 & +25.9 & +29.0 & 0.89 \\
\hline $6 \rightarrow 7 ; \rho_{\min }=0.6 \rho_{c}$ & -0.207 & -79.1 & -103.4 & 0.76 \\
\hline $7 \rightarrow 1 ; P_{\min }=P_{c}$ & -0.153 & -32.6 & -43.2 & 0.76 \\
\hline$\Sigma_{(I I)}=\left| \pm \sum\right|$ & 0.360 & 111.7 & 146.6 & 0.76 \\
\hline
\end{tabular}

its compression and 2) the acceleration of a flow at its expansion. Both stages are well separated one from another by the $P_{\max }$-point shown in Figs. 1-3, for example.

Of course, the influence of output and/or input heats on the above pressures of compression and/or expansion is crucial for the closed contours of stirlings. The regeneration of heat is the necessary, in the certain sense, tool to tune the appropriate stationary regime of the fluid flows. However, the main conclusion about the specific velocity field remains invariable even if one takes into account in full detail the heatmass-momentum transfer process by the generalized Bernoulli law. This result provides a remarkable possibility to estimate a priori the values of a convective velocity for the different segments of CSH-cycle on the base of, exclusively, changes reported in Table 2 (i.e. without the numerical integration of the aforementioned system of non-linear equations). Such information might be vital for the development and further optimization of a real cycle. 


\subsection{Comparison of CSH-stirling with the Brayton cycle by FT-methodology} of caloric diagram. Any comparative analysis of cycle's efficiency (either of socalled ideal efficiency $\eta=1-T_{C} / T_{H}$ allowed by the Second Law or its diminished value termed the effective coefficient $\eta_{e} \lesssim 0.5 \eta_{T}[1,9]$ of the thermodynamic perfection) needs the objective "tool" for comparison of different options. The caloric $(T, s)$ diagram provides, at least, the most usable information for this aim [1,9] but its restrictions are also obvious and have to be noted.

The scales of specific entropy $S(T, \rho)$ and of the other caloric functions $e(T, \rho)$, $h(T, \rho)$ should be universally consistent with Third Law. This requirement is not fulfilled in many practical applications [2-6] based on a unified fundamental EOS. One chooses, for example, for water, the zero-value of saturated liquid $s_{l}\left(T_{t}, P_{t}\right)=0$, at the temperature of triple (or melting) point and its negligible pressure. FT-methodology proposes the simplified PCS-motivated choice of CP-parameters with the following universal constraint for $s$-dependent properties (see Table 3 below):

$$
s_{c}=1.0 \mathrm{~kJ} /(\mathrm{kg} \cdot \mathrm{K}) ; \quad \mu_{c}=h_{c}-T_{c} s_{c}=0 .
$$

The theoretical advantage of such a critical entropy $s_{c}$-universality adopted for all pure substances is obvious. It is a possibility for a further consistent and compatible molecular-dynamic MD-computation of the thermodynamically unmeasurable entropy. It is based exclusively on properties of the Hamiltonian dynamics and the given LJ-potential energy of a finite-volume (N,V)-system. It is known in the framework of statistical mechanics that $s$-dependent properties are not the explicit functions of the phase-space coordinates of $(\mathrm{N}, \mathrm{V})$-system, such as Hamiltonian, temperature and pressure. In contrast, the quantities from Eq.(18) depend on the total phase-space volume accessible to the $(N, V)$-system including itself $s$ and $f(T, \rho)=e(v, s)-T s$, $\mu(T, P)=h(P, s)-T s$. FT-model replaces by the well-founded thermodynamic EOS $(9,10)$ these reversible correlations adopted exclusively for GPhs-states. The aim is a consideration of real processes by the more realistic (measurable) irreversible changes of caloric functions $e(v, T)$ and $h(T, P)$ from Eqs.(19-20) in [14]. On the contrary, the whole classical PhT1-theory [11] is based on the equilibrium concept of reversibility postulating an equivalence of $(l \rightarrow g)$ - and $(g \rightarrow l)$-transitions $\left(\Delta_{l g} h=-\Delta_{g l} h\right)$ between two GPhs-states mimicked namely by $s$-dependent functions.

The deviations of real adiabatic compression and expansion from their isoentropic "counterparts" in the ideal Brayton cycle arise as a result of irreversibility. Simultaneously, the unavoidable pressure drops during heat addition to the working fluid and heat rejection from it are concomitant phenomena of the same physical reason. However, the former factor maintains the available ideal efficiency $\eta_{T}$ while the latter factor reduces it crucially (see Subsection 2.2 and Eq.(7) for explanation). There are two main types of Brayton cycles: 1) the gas turbine operated on an open contour that is heated directly using a combustor; 2) the closed loop that is heated indirectly using a heat exchanger (heater). It is naturally to compare below the proposed CSHstirling only with the latter variant of Brayton cycle. It can be realized either with the 


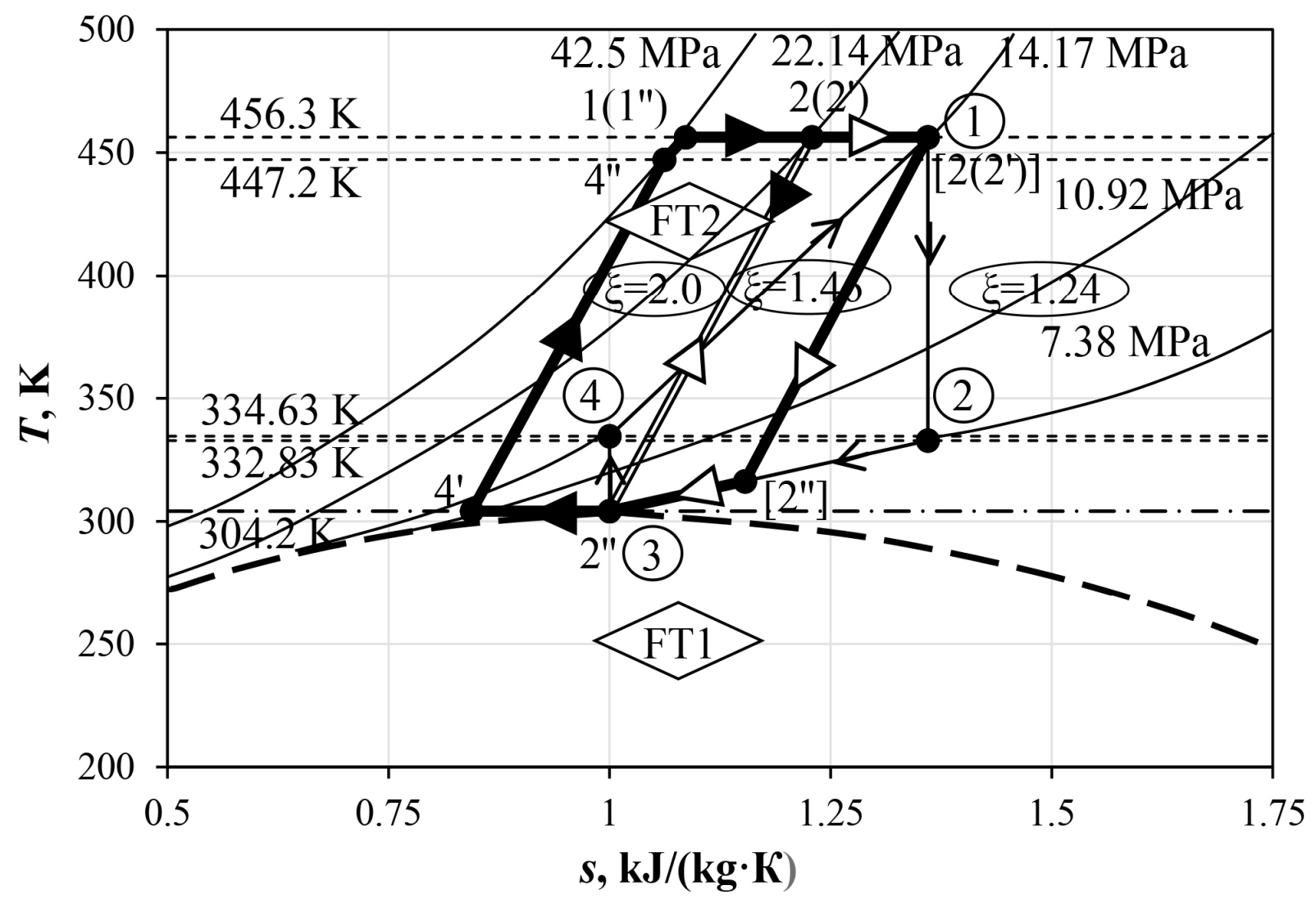

Fig. 5. Comparison of the re-established $T, s$-diagram for CSH-stirling cycle with that for the Bryton cycle of gas turbine (in three variants of $P_{\max }=10.92 \mathrm{MPa}$, $P_{\max }=14.17 \mathrm{MPa}, P_{\max }=22.14 \mathrm{MPa}$ taken at the common difference $\Delta T=456.3 \mathrm{~K}-304.2 \mathrm{~K}$ )

external recuperation of heat as the semi-closed $\mathrm{SCF} / \mathrm{CO}_{2}$ power cycle or without it as well as without the inherent regeneration of heat similar to that in the Stirling and/or Ericsson cycles. The typical temperature and pressure [4,5] can be up to 1000 $\mathrm{K}$ and $30 \mathrm{MPa}$, respectively, for the indirectly heated closed Brayton cycle on $\mathrm{CO}_{2}$ while be up $1500 \mathrm{~K}$ and $30 \mathrm{MPa}$ for the directly fired its variant on $\mathrm{CO}_{2}$. At the same time, the typical operating conditions of stirlings on the working light fluids $\left(\mathrm{He}, \mathrm{H}_{2}\right)$ can be up to $900 \mathrm{~K}$ and up to $40 \mathrm{MPa}$, respectively [1].

Such comparison leads to the compatible estimates of the ideal efficiency $\eta_{T}^{B} \approx 2 / 3$ if the common minimum temperature of both (Brayton and Stirling) cycles is accepted approximately: $T_{C}=300 \mathrm{~K} \approx T_{c}\left(\mathrm{CO}_{2}\right)$. The plausible estimate of the effective thermodynamic perfection should be about: $\eta_{e}^{B} \approx 1 / 3$ or less in this case. On the other hand, the recommended (Section 2) temperature range of CSH-stirling seems to be a priori too reduced because it leads only to the $\eta_{T}^{C S H}=1 / 3$-value. The primary objective of comparison illustrated by Fig. 5 is to argue the much higher level of the effective thermodynamic perfection achievable for CSH-stirling. It leads without the extraneous increase of maximum $T_{H}$-value to the similar realistic value: $\eta_{e}^{C S H} \approx 0.9 \cdot \eta_{T}^{C S H}=0.3$. Simultaneously, one obtains the much more value of the so- 
Table 3. The input CP-parameters of FT-methodology represented for carbon dioxide, water and argon (for comparison).

\begin{tabular}{|c|c|c|c|c|c|c|}
\hline Fluid & $T_{c}, \mathrm{~K}$ & $P_{c}, \mathrm{MPa}$ & $\rho_{c}, \mathrm{~kg} / \mathrm{m}^{3}$ & $s_{c}, \mathrm{~kJ} /(\mathrm{kg} \cdot \mathrm{K})$ & $h_{c}, \mathrm{~kJ} / \mathrm{kg}$ & $e, \mathrm{~kJ} / \mathrm{kg}$ \\
\hline $\mathrm{CO}_{2}$ & 304.2 & 7.38 & 468 & 1.0 & 304.2 & 288.4 \\
\hline $\mathrm{H}_{2} \mathrm{O}$ & 647.1 & 22.06 & 322 & 1.0 & 647.1 & 578.6 \\
\hline $\mathrm{Ar}$ & 150.7 & 4.86 & 531 & 1.0 & 150.7 & 141.5 \\
\hline
\end{tabular}

called relative specific (per unit of mass) power of engine $\xi$ [1] due to the significant increase of the maximum pressure in the CSH-stirling: $P_{\max }=42.5 \mathrm{MPa}$ :

$$
\xi \approx\left(P_{\max }+P_{\min }\right) / 2 P_{\min } \text {. }
$$

Its more detailed calculation is often too complicated even for the primitive ig-cycles.

Therefore, we have used the simplified Eq.(19) to estimate three preliminary variants of $\xi$-value for the Brayton cycle and for the CSH-stirling depicted on the respective isobars $P_{\max }$ in Fig. 5. The input thermal and caloric CP-data for $\mathrm{CO}_{2}$ obtained in accordance with Eq.(18) are represented in Table 3. For the correct comparison, three Brayton cycles working on $\mathrm{SCF} / \mathrm{CO}_{2}$ were chosen from $[3,4]$ with the common constraints: $P_{\min }=P_{c}\left(C O_{2}\right)=7.38 \mathrm{MPa}$ and $\eta_{T}=1-304.2 / 456.3=1 / 3$ but with the different $P_{\max }$-values. The respective range of $\xi$-values: $\xi^{B}\left(P_{\max }=10.92 \mathrm{MPa}\right)=1.24 ; \quad \xi^{B}\left(P_{\max }=14.17 \mathrm{MPa}\right)=1.46, \quad \xi^{B}\left(P_{\max }=22.14 \mathrm{MPa}\right)=2.0$; $\xi^{C S H}\left(P_{\max }=42.5 \mathrm{MPa}\right)=3.38$ demonstrates the obvious advantage of CSH-stirling. The role of FT2-region and its highly compressible states in this resulting efficiency of CSH-stirling is very essential. The loop of an intermediate Brayton cycle: 1-2-3-41 with $P_{\max }=14.17 \mathrm{MPa}$ is shown in Fig. 5 by the thin lines with arrows to compare it with the proposed CSH-stirling depicted by the bold lines on the same (T,S)-plane.

5. Conclusions It is useful to compare, in brief, the main steps of the traditional analysis in energetics and/or refrigeration with the discussed FT-methodology. Since the adequate SCF-EOS cannot be considered as an ig-EOS, any ig-based results [1] are only for a quantitative draft of cycle and not meant to do its realistic approximation. Then, the unavoidable and formidable stage of trials and errors starts to achieve the reasonable scheme for a practical realization. The following stage should establish the consistent thermodynamic model of a closed loop based usually on the mass and energy balance differential equations as well as on the detailed thermophysical information on the chosen working SCF-fluid. The knot-points of a concluding contour have to be calculated through iterations. At last, the primary objective of the further testing is to achieve steady operating conditions with a possibility to control the dynamical stationary process by the appropriate external interferences. The described cumbersome sequence of actions is, in fact, semi-empirical. Its main resultant estimate of $\eta_{e}$-coefficient seems to be often rather elusive and, as a rule, overestimated by authors.

FT-methodology is an attempt to elucidate the above problems in the step-by step manner from the strictly thermodynamic viewpoint. It leads immediately to the fundamental distinction between the gibbsian formulation of the supposedly reversi- 
ble quasiequilibrium (quasistatic) paths and that based on the thermodynamic homogeneous EOS from Eqs. $(9,10)$ and on its consequences for the heterogeneous NGFstates of Eq.(13). More accurately, the introduced by Eq.(1) coupled criterion of the thermophysical perfection $\gamma^{F T}$ can be easily represented by the universal forms for heat engine $(H)$ and heat pump $(C)$, respectively:

$$
\begin{aligned}
& \gamma_{H}^{F T}=1-(\partial e / \partial s)_{T} /(\partial e / \partial s)_{v}=1-T_{i n t} / T^{G}, \\
& \gamma_{C}^{F T}=1-(\partial e / \partial v)_{T} /(\partial e / \partial v)_{s}=1+P_{i n t} / P^{G},
\end{aligned}
$$

were the Maxwell's equality: $(\partial P / \partial T)_{v}=(\partial s / \partial v)_{T}$ has been used in Eq.(20). Both gibbsian definitions denoted here by the upper index $G$ and following from the local thermodynamic potential [11] of internal energy $e(v, s)$ cannot provide the exact equalities $\left(T_{\text {int }}=T^{G}\right.$ and $\left.P_{i n t}=P^{G}\right)$ with the internal thermodynamic fields $\left(T_{\text {int }}, P_{\text {int }}\right)$. In opposite case, the local dynamical criterion of the thermophysical perfection $\gamma^{F T}$ will tend to the degenerated zero-value at a singular (non-existent) equilibrium state in which the slopes of $T$ - and $v$-isolines coincide (the Stirling cycle becomes impossible) in the $(e, s)$-plane as well as the slopes $T$ - and $s$-isolines coincide (the Carnot cycle becomes impossible) in the $(e, v)$-plane.

On the other side, both isothermal consequences of Eqs. $(20,21)$ are completely consistent with the First and Second Law effects for the local dynamical variables calculated at the external given temperature:

$$
\begin{aligned}
& T_{i n t}=(\partial e / \partial s)_{T}, \\
& P_{i n t}=(\partial e / \partial v)_{T} .
\end{aligned}
$$

The isothermal reduced bulk modulus is a certainly mechanical property, which becomes also definable by the above dynamical variables including the inherent FTinterpretation of a specific entropy: $\Delta_{T} s=\Delta_{T} e / T_{\text {int }}$ [13]:

$$
\frac{\beta_{T}^{i g}}{\beta_{T}} \equiv \frac{1}{\rho k T \beta_{T}}=v^{2}\left\{\left[\frac{\partial^{2}\left(e / k T_{i n t}\right)}{\partial v^{2}}\right]_{T}-\left[\frac{\partial^{2}(s / k)}{\partial v^{2}}\right]_{T}\right\} .
$$

We have applied the FT-methodology to SCF-region, in total [14], and to the proposed CSH-stirling, in particular, with the interesting and promising, to our mind, results.

\section{References:}

1. Walker G. Stirling Engines. - Clarendon Press, Oxford, 1980 - 534p.

2. Chen H., Goswami D. Y., Stefanakos E. K. A review of thermodynamic cycles and working fluids for the conversion of low-grade heat // Renewable and Sustainable Energy Reviews. - 2010. - Vol. 14. - P. 3059-3067.

3. Iverson B. D., Conboy T. M., Pasch J. J., Kruizenga A. M. Supercritical $\mathrm{CO}_{2}$ Brayton cycles for solar-thermal energy // Applied Energy. - 2013. - Vol. 111. P. 957-970.

4. Geng C., Shao Y., Zhong W., Liu X. Thermodynamic analysis of supercritical $\mathrm{CO}_{2}$ power cycle with fluidized bed coal combustion // Hindawi Journal of Combustion. -2018 . - P. 1-9. 
5. Zhu $Q$. Innovative power generation systems using supercritical $\mathrm{CO}_{2}$ cycles // Review Article. Clean Energy. - 2017. - Vol. 1. - P. 68-79.

6. Chen Y., Lundquist P., Johsnsson A., Platell P. A comparative study on the carbon dioxide transcritical power cycle compared with an organic Rankine cycle with R123 as working fluid in waste heat recovery // Applied Thermal Engineering. - 2006. - Vol. 26. - P. 2142-2147.

7. Haken H. Synergetics. - Mir, M.: 1980. - 367p.

8. Koch $S$. $W$. Dynamics of First-Order Phase Transition in Equilibrium and Nonequilibrium Systems / In Lecture Notes in Physics. - Springer-Verlag, Berlin Heidelberg, New-York, Tokyo, 1984. - 214p.

9. Wurm J., Kinast J. A., Roose T. R., Staats W. R. Stirling and Vuilleumeir heat pumps. - McGraw-Hill Inc., NY,USA, 1990. - 252p.

10. Novikov I. I. Phase Transitions and Critical Points between Solid Phases. - M., Nauka, 2008. - 161p.

11. Rumer Yu. B., Rivkin M.Sh. Thermodynamics, Statistical Physics and Kinetics. M., Nauka, 1972. - 305p.

12. Brand J. I. Equations of state for supercritical process development // in Proceedings of $12^{\text {th }}$ Symposium on Thermophysical Properties, Boulder, Colorado, USA, 1994. - P. 1-5.

13. Rogankov V. B. Asymmetry of heterophase fluctuations in nucleation theory // in Nucleation Theory and Applications (edited by J.W.P.Schmelzer, G.Röpke and V.B.Priezjev) Chapt. 22, Dubna, JINR, 2011. - P. 325-337.

14. Rogankov V. B., Shvets M. V., Rogankov O. V., Chikunkova T. A. Supercritical heterogeneous nanostructure of fluids. Part 1. Diagram of fluctuation transitions in non-gibbsian phases // Физика аэродисперсных систем. - 2019. - №56. C. 14-30.

15. Goodyear G., Maddox M. W., Tucker S. Correlation between local and long-range structure in compressible supercritical Lennard-Jones fluids: state-point dependence // J.Phys.Chem. - 2000. - Vol. 104 B. -P. 6258-6265.

16. Rogankov O. V., Mazur V. A., Rogankov V. B. The critical parameters and congruent vapor-liquid diagram of ten metallic alkali and alkaline earth fluids and one H-bond organic (methanol) // Fluid Phase Equilibria. - 2018. - Vol. 455. - P. 1523.

17. Rogankov V. B., Boshkov L. Z. Gibbs solution of the van der Waals-Maxwell problem and universality of the liquid-gas coexistence curve // Phys. Chem. Chem. Phys. - 2002. - Vol. 4. - P. 873-878.

18. Rogankov V. B., Levchenko $V$. I. Global asymmetry of fluids and local singularity in the diameter of the coexistence curve // Phys.Rev. E. - 2013. - Vol. 87. - P. 118

19. Rogankov V.B. Fluctuational-thermodynamic interpretation of small angle X-ray scattering experiments in supercritical fluids // Fluid Phase Equilibria. - 2014. Vol. 383. - P. 115-125.

20. Rogankov Jr. O.V., Mazur V.A., Shvets M.V.and Rogankov V.B. Re-established congruent vapor-liquid diagram of alkali fluid metals as alternative to crossover VLE-interpretation // Fluid Phase Equilibria. - 2018. - Vol. 466. - P. 79-88. 
21. Levelt Sengers J.M.H.Critical behavior of fluids: concept and applications, in Supercritical Fluids, E.Kiran and J.M.H.Levelt Sengers (eds.), (1994) US Government (Printed in the Netherlands) 3-38.

22. Kostrowizka-Wyczalkowska A.K., Sengers J.V., Anisimov M.A. Critical fluctuations and the equation of state of van der Waals // Physica A. - 2004. - Vol. 334. - P. 482511.

23. Woodcock L. V. Thermodynamics of criticality: percolation loci, mesophases and a critical dividing line in binary-liquid and liquid-gas equilibria // Journal of Modern Physics. - 2016. - Vol. 7. - P. 760-773.

\title{
Роганков В. Б., Швець М. В., Роганков О. В., Чікункова Т. О. Надкритична гетерогенна наноструктура флюїдів. Частина 2. Її потенційний вплив на створення зчеплених стірлінгів 3 проміжною регенерацісю тепла
}

\begin{abstract}
АНОТАЦІЯ
Запропоновано нову концепиію області надкритичної флюїдної поведінки щчоб пояснити сукупність нових експериментальних і чисельних результатів, в яких загальноприйнята теорія асимптотичного скейлінгу та ї̈ розширення на більший інтервал параметрів досягають межі придатності. Існування гетерогенної стаціонарної наноструктури гратового типу в широких діапазонах надкритичних властивостей, щзо була названа негіббсівською фазою флюїду, було запропоноване В.Б.Роганковим у рамках моделі ФТ (флуктуаційної термодинаміки). Практичне використання такої флюїдної структури може бути досить перспективним. Зокрема, запропонована тут конщепція спряженого надкритичного гетерогенного теплового двигуна може бути реалізована на практиці. Він складається з двох зв'язаних між собою ичиклів типу СтірлінгаРейліса зі стандартними пристроями регенерачї $i$, крім того, з проміжною (внутрішньою) рекуперачією теплоти. Замкнена (тобто ізольована від навколишнього середовища) конструкиія обох субииклів $i$ запропонованого об'єднуючого стірлінга, в цілому, $\epsilon$ його перевагою у порівнянні з зовнішніми формами рекуперації у цииклах внутрішнього згоряння. Таким чином, наша мета полягає у використанні виявлених нанодисперсних властивостей флюїду для формулювання конщепиії створення ефективного ичиклу Стірлінга з перспективним робочим тілом, в якості якого в роботі запропоноване використання діоксиду вуглецю замість звичайного у иій проблемі використання легколетючих водню або гелію, які створюють багато проблем з використанням звичайних стірлінгів.

Ключові слова: діаграма флуктуачійних переходів, цикли типу Стірлінга-Рейліса, регенерація і внутрішня рекуперація теплоти, екологічна безпека замкнутих теплових ииклів.
\end{abstract}


Роганков В. Б., Швец М. В., Роганков О. В., Чикункова Т. А.

\title{
Сверхкритическая гетерогенная наноструктура флюидов. \\ Часть 2. О потенциально-возможном создании сопряженных стирлиннгов с промежуточной регенерацией теплоты
}

\begin{abstract}
АННОТАЦИЯ
Предложена новая конщепџия сверхкритической флюидной (СКФ) области с целью интерпретации ряда экспериментальных и полученных численными методами наблюдений, в которых использование принятой асимптотической теории скейлинга и ее кроссоверного расширения достигает предела применимости. Существование устойчивой, решеточного типа, гетерогенной наноструктуры в широких интервалах сверхкритических параметров, названной негиббсовской флюидной (НГФ)-фазой, было гипотетически сформулировано В.Б. Роганковым в рамках модели флуктуационной термодинамики (ФТ). Практическое использование такой флюидной структуры может дать многообещающие результать. В частности, здесь предложена идея и дань рекомендачии по созданию сопряженного сверхкритического гетерогенного (ССГ) теплового двигателя, типа ичкла Стирлинга. Он образован двумя спаренными вдоль критической изохоры рабочего флюида под-ииклами, содержащими не только стандартные устройства регенерации теплоты, но и, дополнительно, включающими схему ее внутренней (для замкнутого ичикла) рекуперации. Замкнутые контуры обоих подциклов и ССГ-контура, в иелом, обуславливают их экологически-безопасную схему реализачии и, таким образом, значительные преимущества по сравнению с двигателями внутреннего сгорания, работающими по открытому ичиклу с внешней рекуперащией теплоты. Отсюда, целью данной части работы является обоснование возможности использования области нанодисперсных НГФ-свойств в комбинации с наиболее подходящими СКФ (двуокисью углерода), обнаруженной нами в предыдущей части, для создания эффективных двигателей типа стирлинга, без обязательно применения в них легко-летучих гелия и водорода, создающих множество известных проблем практической эксплуатации.
\end{abstract}

Ключевые слова: диаграмма флуктуачионных переходов, ичикль типа СтирлингаРейлиса, регенерация и внутренняя рекупераџия теплоты, экологическая безопасность замкнутых тепловых ичилов. 